\title{
Fourth-Generation Analogues of the Anticancer Peptaibol Culici- nin D: Probing the Effects of Hydrophobicity and Halogenation on Cytotoxicity
}

\author{
Johanes K. Kasima,b \\ Iman Kavianinia*a,c \\ Matthew Bullb,d \\ Paul W. R. Harris ${ }^{a, c}$ \\ Jeff B. Smaillb,d \\ Adam V. Patterson ${ }^{b, d}$ \\ Margaret A. Brimble*a,c (iD) \\ a School of Biological Sciences, The University of Auckland, \\ 3A Symonds Street, Auckland 1010, New Zealand \\ I.kavianinia@auckland.ac.nz \\ m.brimble@auckland.ac.nz \\ b Maurice Wilkins Centre for Molecular Biodiscovery, The \\ University of Auckland, Private Bag 92019, Auckland \\ 1010, New Zealand \\ ' School of Chemical Sciences, The University of Auckland, \\ 23 Symonds Street, Auckland 1010, New Zealand \\ dAuckland Cancer Society Research Centre, Faculty of \\ Medical and Health Sciences, The University of Auckland, \\ Private Bag 92019, Auckland 1010, New Zealand \\ Published as part of the \\ Special Issue dedicated to Prof. Sarah Reisman, recipient of the \\ 2019 Dr. Margaret Faul Women in Chemistry Award
}

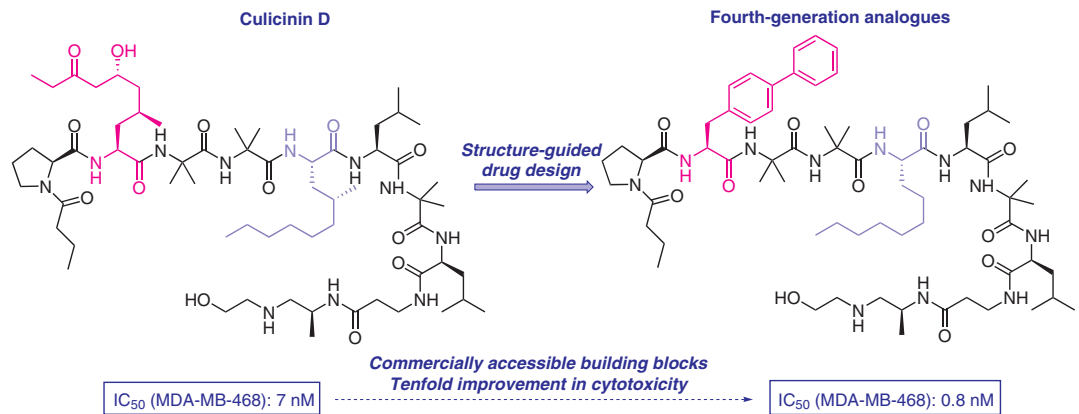

Received: 11.03 .2021

Accepted after revision: 26.04.2021

Published online: 10.06 .2021

DOI: 10.1055/s-0040-1706264; Art ID: ss-2021-m0124-op

Abstract Preliminary results of the effect of hydrophobicity and halogenation on the cytotoxicity of the anticancer peptaibol culicinin $D$ are reported. Building on previous work, the synthetically challenging $(2 S, 4 S, 6 R)$-2-amino-6-hydroxy-4-methyl-8-oxodecanoic acid and (2S,4R)-2-amino-4-methyldecanoic acid building blocks were replaced with derivatives of $\mathrm{L}$-phenylalanine and 2 -aminodecanoic acid, respectively. Substitution of $(2 S, 4 S, 6 R)$-2-amino-6-hydroxy-4-methyl-8-oxodecanoic acid with L-4,4'-biphenylalanine yielded an analogue that was tenfold more potent than the natural product and was also the most hydrophobic analogue, as judged by an antiproliferative $\mathrm{IC}_{50}$ assay and $\log \mathrm{D}$ calculations; these results suggest that the potency of culicinin $\mathrm{D}$ may be governed by its hydrophobicity. However, the introduction of halogenated moieties into the peptide sequence generated analogues that were similarly potent, although not necessarily hydrophobic. Thus, the parameters regulating the cytotoxicity of culicinin $D$, and by extension other peptaibols, are multimodal and include both halogenation and hydrophobicity.

Key words anticancer compounds, peptides, peptaibols, culicinin D, hydrophobicity, halogenation, cytotoxicity

The peptaibol culicinin D (1) was first isolated by He and colleagues from the entomopathogenic fungus Culinomyces clavisporus strain LL-12I252. ${ }^{1}$ Elucidation of the structure was undertaken with 2D NMR and MS analyses, which identified the presence of several non-canonical amino acids, including 2-aminoisobutyric acid (Aib), a characteristic residue of the peptaibol class of peptides, as well as $(2 S, 4 S, 6 R)$-2-amino-6-hydroxy-4-methyl-8-oxodecanoic acid (AHMOD), (2S,4R)-2-amino-4-methyldecanoic acid (AMD), and the C-terminal amino alcohol 2-(2'-aminopropyl)aminoethanol (APAE). The $\mathrm{N}$ terminus was also found to be acylated by a butyryl moiety. Culicinin D was subsequently found to display a selective low nanomolar antiproliferative activity against the phosphatase and tensin homologue (PTEN)-negative MDA-MB-468 breast tumour cell line, with an $\mathrm{IC}_{50}$ value of $7 \mathrm{nM}$. This has important implications for anticancer therapy, given that this cell line does not express the pten gene, which encodes the tumour suppressor protein PTEN. The absence of this protein in turn promotes constitutive activation of the PI3K/AKT/mTOR pathway, ${ }^{2}$ driving unregulated cellular proliferation as an established hallmark of cancer. ${ }^{3}$ Culicinin $D$ is therefore positioned as a suitable candidate for total synthesis and further SAR studies.

Zhang and co-workers were the first to report the preparation of the C-terminal pentapeptide fragment of this peptide. ${ }^{4}$ Our group then embarked on the total synthesis of the full-length peptide, employing the Fmoc/tBu SPPS strategy. ${ }^{5}$ In this initial work, we also established a revision of the absolute stereochemistry of the C-6 atom in the $(2 S, 4 S, 6 R)$-AHMOD residue to $6 R$, from the initially reported $6 S$ (Figure 1 ). 


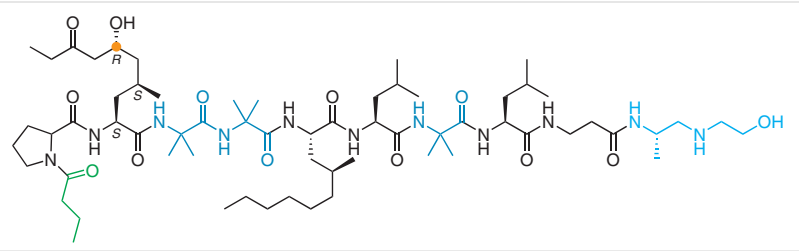

Figure 1 Revised structure of the anticancer peptaibol culicinin D (1), with the three key structural features of peptaibols and the C- 6 atom on the $(2 S, 4 S, 6 R)$-AHMOD moiety highlighted

Subsequent optimisations of the synthetic methodology culminated in the development of a novel hybrid solid/solution-phase protocol, wherein the APAE moiety was installed in the solution phase after assembly of the peptide backbone on resin, affording the title peptide in better yield for biological testing. ${ }^{6,7}$ We then proceeded to generate a library of culicinin D analogues, with the intention of identifying key residues contributing to the bioactivity of this peptide. $^{7-9}$

During these endeavours, we established that substitution of the synthetically challenging (2S,4S,6R)-AHMOD (highlighted in pink, Scheme 1) and (2S,4R)-AMD (highlighted in purple, Scheme 1) residues with the commercially accessible building blocks L-cyclohexylalanine (Cha) (highlighted in yellow, Scheme 1) and (S)-2-aminodecanoic acid (AD) (highlighted in cream, Scheme 1), respectively, afforded analogue 3, which was found to be equipotent to the natural product in an antiproliferative $\mathrm{IC}_{50}$ assay. ${ }^{8}$ Further examination of the $N$ and $C$ termini by replacement of the native butanoyl (highlighted in green, Scheme 1) and/or APAE (highlighted in blue, Scheme 1) moieties, respectively (4), with a variety of suitable functional groups was generally well-tolerated but unfortunately did not yield any analogues with appreciable improvement in bioactivity (Scheme 1). ${ }^{9}$

Having serendipitously identified that substitution of the $(2 S, 4 S, 6 R)$-AHMOD moiety with the structurally dissimilar L-cyclohexylalanine afforded an equipotent peptide in terms of the $\mathrm{IC}_{50}$ value, we arrived at the conclusion that its role is likely not critical for the bioactivity of culicinin D. However, potential synthetic challenges in the introduction of further substituents on the cyclohexyl ring of $\mathbf{3}$ led us to revisit our earlier series of analogues. We identified the aromatic analogue $\mathbf{5}$, containing L-phenylalanine in place of $(2 S, 4 S, 6 R)$-AHMOD, ${ }^{8}$ as a more suitable starting point, given the relative ease of accessibility of its Fmoc-protected derivatives for site-specific incorporation into the peptide sequence by SPPS.

In this paper, we report the preparation of a fourth generation of culicinin D analogues in our compound library. We have elucidated the role of different substituents on the phenyl side chain on the overall bioactivity of culicinin D. The analogues prepared in this work were evaluated for
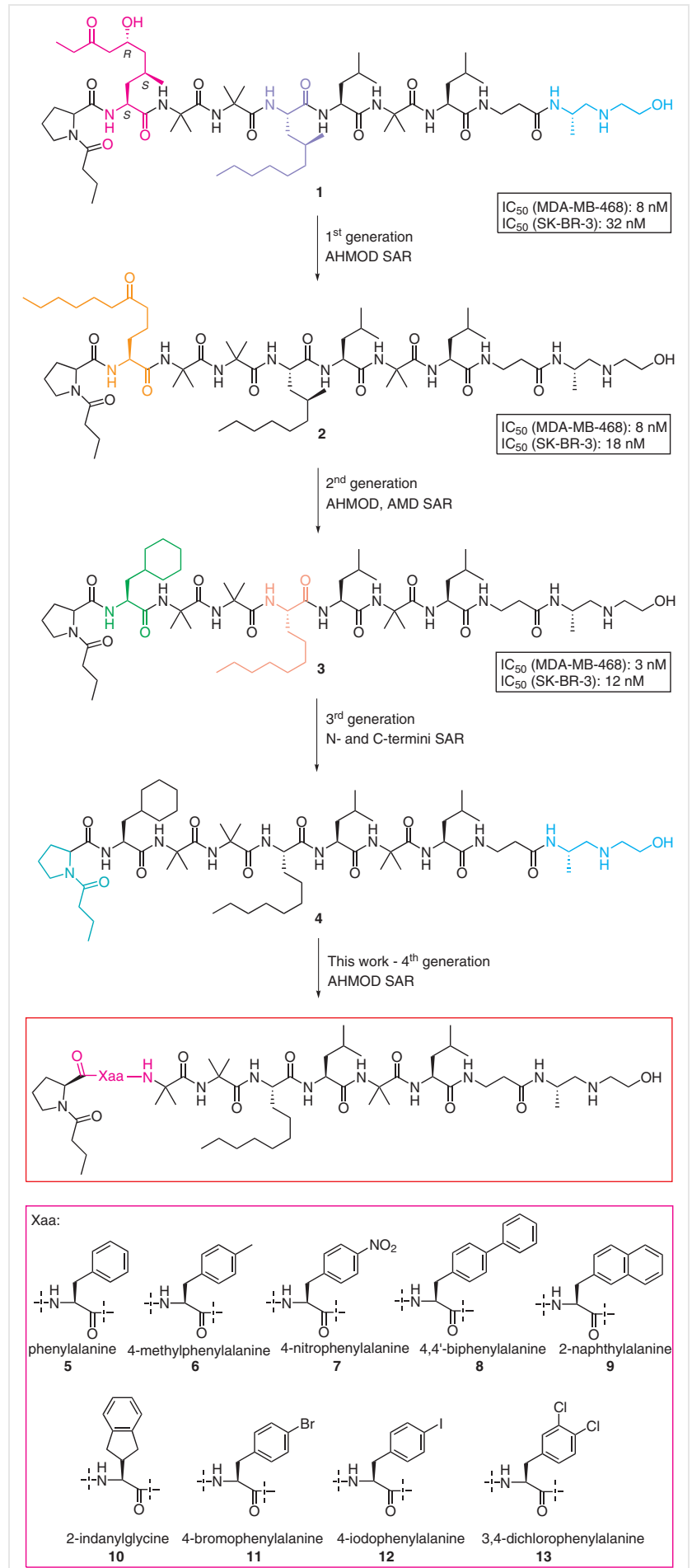

Scheme 1 Summary of synthesised culicinin D analogues for SAR studies

their antiproliferative activity by using an $\mathrm{IC}_{50}$ assay, providing detailed information on the influence of the different side-chain groups on peptide cytotoxicity. 
Fmoc/tBu SPPS of the eight culicinin D analogues 6-13 commenced on 2-chlorotrityl chloride (2-CTC) resin (loading: $0.89 \mathrm{~g} / \mathrm{mol}$ ) (Scheme 2). Fmoc- $\beta$ Ala-OH was first loaded on the resin by using DIPEA as a base. The unreacted chloride functionalities were then capped by using $\mathrm{CH}_{2} \mathrm{Cl}_{2}$ / $\mathrm{MeOH} / \mathrm{DIPEA}(8: 1.5: 0.5$,). Removal of the Fmoc protecting group was effected with $20 \%$ piperidine/DMF and was followed by double acylation of the subsequent Fmoc-protected amino acids with HATU and DIPEA as the coupling reagents, with the exception of the single consecutive AibAib coupling, for which COMU, Oxyma, and DIPEA were employed instead. These latter reagents have been previously shown to be efficacious in our preparation of the structurally related peptaibol trichoderin A. ${ }^{10}$

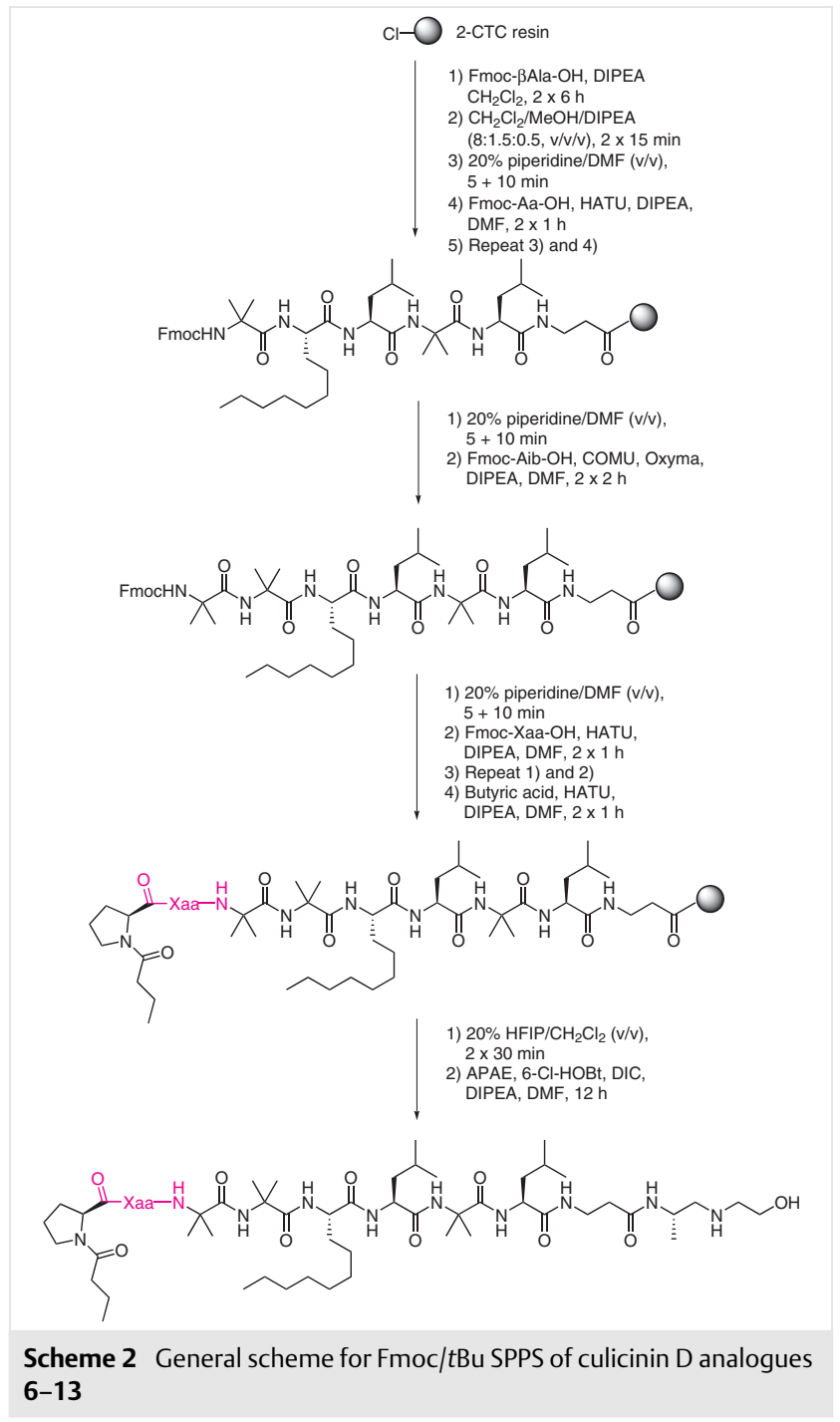

Cleavage of the peptidyl resin was effected with $20 \%$ $\mathrm{HFIP} / \mathrm{CH}_{2} \mathrm{Cl}_{2}$, after which the lyophilised peptide was subjected to late-stage solution-phase installation of the APAE moiety in the presence of 6-Cl-HOBt, DIC, and DIPEA. Upon completion of this reaction, as judged from analytical RPHPLC and ESI-MS, the crude product was purified by semipreparative RP-HPLC, yielding the desired peptide for further biological studies. The yields of $\mathbf{6 - 1 3}$ ranged from 3.6 to $17.2 \%$ and all compounds were recovered at $>98 \%$ purity. Fmoc/tBu SPPS of reference compounds $\mathbf{3}$ and $\mathbf{5}$ was also carried out as previously reported.,

The synthesised culicinin D analogues 6-13 were subsequently assayed for their growth inhibitory effects on two human-derived breast cancer cell lines: SK-BR-3 and MDAMB-468. Cells were first incubated overnight at $37{ }^{\circ} \mathrm{C}$ and $5 \% \mathrm{CO}_{2}$ to allow adherence, prior to addition of the peptide, with threefold serial dilution, and incubation for a further five days. Changes in cellular viability were quantified with the sulforhodamine $\mathrm{B}$ (SRB) assay ${ }^{11}$ in terms of the $\mathrm{IC}_{50}$ value, which was obtained by interpolating the peptide concentration required to halve the staining intensity relative to that of the control wells on the same 96-well plate (Table 1).

In general, the analogues tested exhibit greater potency against the MDA-MB-468 cell line than the SK-BR-3 cell line. Compound 8 , in which the $(2 S, 4 S, 6 R)$-AHMOD was replaced with L-4,4'-biphenylalanine, was found to be most potent against both cell lines, with $\mathrm{IC}_{50}$ values of 0.83 and $8.30 \mathrm{nM}$, respectively, whereas compound 7, bearing an L-4nitrophenyl group, was the least potent with $\mathrm{IC}_{50}$ values of 11.20 and $46.88 \mathrm{nM}$. One possible reason for this marked difference in activity, relative to that of reference compound $\mathbf{5}$, might be the increased overall hydrophobicity of $\mathbf{8}$, given the presence of the biphenyl moiety on the side chain of the peptide.

The hydrophobicity of any peptide can be approximated by means of the retention time on analytical RP-HPLC; hydrophobic compounds are expected to elute later in the chromatogram. ${ }^{12,13}$ In support of our postulate, the most potent compound, 8, eluted latest ( $\left.t_{\mathrm{R}}: 25.50 \mathrm{~min}\right)$, whereas the least potent peptide, 7, eluted earliest $\left(t_{R}: 22.43 \mathrm{~min}\right)$ (see the Supporting Information). A more reliable quantifier of hydrophobicity is the parameter $\log \mathrm{D}$, or the octanol/water distribution coefficient. ${ }^{14}$ The $\log \mathrm{D}$ value for each compound at physiological $\mathrm{pH}$ value (i.e. 7.4) was thus calculated on the basis of the respective chemical structures, with higher $\log \mathrm{D}$ values correlating to greater hydrophobicity. ${ }^{15}$ The introduction of the different substituents at the para position of the phenyl ring appeared to confer improved peptide hydrophobicity relative to the parent compound $\mathbf{5}$, with the exception of compound $\mathbf{7}$, in which the nitro group instead conferred less hydrophobicity, albeit only minimally. Consistent with our $\mathrm{IC}_{50}$ and RP-HPLC $t_{\mathrm{R}}$ data, the most potent compound, 8, has the largest $\log \mathrm{D}$ value of 3.34 , in contrast to the least potent, 7, with a $\log \mathrm{D}$ value 1.63 .

Previously, Albericio and co-workers showed that the presence of halogenated phenylalanine derivatives in the sequence of the marine-derived cyclic lipodepsipeptide kahalalide $\mathrm{F}$ afforded analogues that were more potent than 
the natural product. ${ }^{16}$ Intrigued by these findings, we subsequently opted to test the reproducibility of this trend on the culicinin D backbone, yielding analogues 11-13. Within this sub-series of analogues, we found that the most potent compound, 11, is also the least hydrophobic, which sug- gests that halogenation of the phenyl ring may influence the bioactivity of culicinin D through a mechanism that is distinct to that imparted by an enhancement in hydrophobicity, yet is equally efficacious.

Table 1 Antiproliferative Activity of Culicinin D Analogues 6-13 against SK-BR-3 and MDA-MB-468 Breast Tumour Cell Lines as Judged by the SRB Assay $^{\mathrm{a}}$

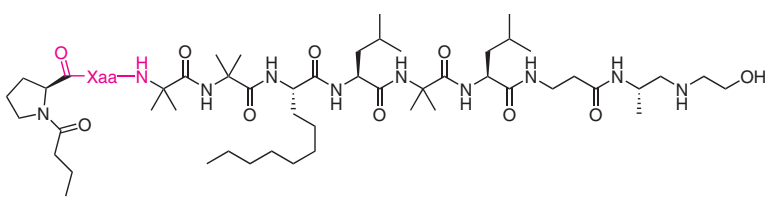

\begin{tabular}{|c|c|c|c|c|c|}
\hline \multirow[t]{2}{*}{ Compound } & \multirow[t]{2}{*}{ Xaa } & \multicolumn{2}{|l|}{$\mathrm{IC}_{50} \pm \mathrm{SEM}(\mathrm{nM})$} & \multirow[t]{2}{*}{$t_{\mathrm{R}}(\min )$} & \multirow[t]{2}{*}{$\log D$} \\
\hline & & SK-BR-3 & MDA-MB-468 & & \\
\hline 3 & & $12.00 \pm 4.70$ & $3.00 \pm 0.20$ & 26.92 & 2.16 \\
\hline 5 & & $25.00 \pm 2.00$ & $7.00+0.20$ & 24.03 & 1.69 \\
\hline 6 & & $12.35 \pm 0.49$ & $3.00 \pm 0.21$ & 24.21 & 2.20 \\
\hline 7 & & $46.88 \pm 1.17$ & $11.20 \pm 2.33$ & 22.43 & 1.63 \\
\hline 8 & & $8.30 \pm 0.85$ & $0.83 \pm 0.74$ & 25.50 & 3.34 \\
\hline 9 & & $15.08 \pm 2.51$ & $6.30 \pm 1.41$ & 25.09 & 2.68 \\
\hline 10 & & $12.95 \pm 3.04$ & $7.30 \pm 0.28$ & 24.82 & 2.10 \\
\hline 11 & & $10.55 \pm 2.05$ & $2.98 \pm 1.59$ & 23.80 & 2.45 \\
\hline
\end{tabular}


Table 1 (continued)

\begin{tabular}{|c|c|c|c|c|c|}
\hline \multirow[t]{2}{*}{ Compound } & \multirow[t]{2}{*}{ Xaa } & \multicolumn{2}{|l|}{$\mathrm{IC}_{50} \pm \mathrm{SEM}(\mathrm{nM})$} & \multirow[t]{2}{*}{$t_{R}(\min )$} & \multirow[t]{2}{*}{$\log \mathrm{D}$} \\
\hline & & SK-BR-3 & MDA-MB-468 & & \\
\hline 12 & & $18.95 \pm 4.24$ & $6.08 \pm 1.73$ & 24.79 & 2.62 \\
\hline 13 & & $10.90 \pm 1.06$ & $3.75 \pm 0.64$ & 24.63 & 2.90 \\
\hline
\end{tabular}

${ }^{a}$ All values are reported in $\mathrm{nM} \pm$ the standard error of mean (SEM) from three independent measurements $(n=3)$, correct to two decimal places. The retention time $\left(t_{R}\right)$ on analytical RP-HPLC and predicted logD value at physiological pH value (pH 7.4) are also included for each analogue. Analogues $\mathbf{3}$ and $\mathbf{5}$ were used as reference compounds in this instance. The shaded entry indicates the most potent compound within the series.

In summary, we have described the synthesis and characterisation of a fourth generation of analogues of the anticancer peptaibol culicinin D, with compound $\mathbf{5}$ as a reference framework, in which the synthetically challenging building blocks AHMOD and AMD have been replaced with L-phenylalanine derivatives and a hydrophobic amino acid, $(S)$-2-aminodecanoic acid (AD), respectively. We identified analogue $\mathbf{8}$, bearing a biphenyl ring on the side chain, as more potent than our current lead compound, 3; it was also the most hydrophobic, based on its analytical RP-HPLC retention time and the $\log \mathrm{D}$ value. This trend, however, does not necessarily apply to other analogues reported herein; this discrepancy likely suggests that the potency of culici$\operatorname{nin} \mathrm{D}$ is not governed solely by its hydrophobicity but also by the different natures of the substituents on the phenyl ring, such as the halogen atoms present in compounds 1113. Further structural studies are anticipated to close this particular gap in knowledge.

All reagents were purchased as reagent grade and used without further purification. $N, N$-Diisopropylethylamine (DIPEA; ReagentPlus), piperidine, butyric acid, high-grade formic acid for LC-MS, and $N, N^{\prime}-$ diisopropylcarbodiimide (DIC) were purchased from Sigma-Aldrich (St Louis, MO). DMF, $\mathrm{CH}_{2} \mathrm{Cl}_{2}$, and MeOH were purchased from ECP Ltd. (Auckland, NZ). Water for RP-HPLC was obtained from the arium pro ultrapure water production system (Sartorius, Gottingen, Germany). $O$-(7-Azabenzotriazol-1-yl)- $N, N, N^{\prime}, N^{\prime}$-tetramethyluronium hexafluorophosphate (HATU) and ethyl 2-cyano-2-(hydroxyamino)acetate (Oxyma) were purchased from Novabiochem (Merck, Darmstadt, Germany). Fmoc- $\alpha$-aminoisobutyric acid (Aib) was purchased from CS Bio (Shanghai, China). 1-[(1-(Cyano-2-ethoxy-2-oxoethylideneaminooxy)dimethylaminomorpholinomethylene)] methanaminium hexafluorophosphate (COMU), 6-chloro-1-hydroxybenzotriazole (6$\mathrm{Cl}-\mathrm{HOBt}$ ), and Fmoc- $\beta$-Ala-OH were purchased from Aapptec (Louisville, $\mathrm{KY}$ ). Acetonitrile $\left(\mathrm{CH}_{3} \mathrm{CN}\right)$ (HPLC and LC-MS grade) was purchased from Merck (Darmstadt, Germany). Trifluoroacetic acid (TFA) was purchased from Scharlau (Barcelona, Spain). 2-Chlorotrityl chlo- ride polystyrene resin (2-CTC), Fmoc-Leu-OH, Fmoc-Phe-OH, and Fmoc-Pro-OH were purchased from CS Bio (Shanghai, China). Fmoc(S)-2-aminodecanoic acid-OH (AD) was purchased from Ark Pharm (Chicago, IL). Fmoc-Cha-OH and 1,1,1,3,3,3-hexafluoro-2-propanol (HFIP) were purchased from AK Scientific (Union City, CA). Fmoc-L4,4'-biphenylalanine- $\mathrm{OH}$, Fmoc-L-4-methylphenylalanine- $\mathrm{OH}$, Fmoc$\mathrm{L}-4$-nitrophenylalanine- $\mathrm{OH}$, and Fmoc-L-4-iodophenylalanine-OH were purchased from Peptech (Burlington, MA). Fmoc-L-3,4-dichlorophenylalanine-OH, Fmoc-L-1-naphthylalanine-OH, Fmoc-L-2-indanylglycine-OH, and Fmoc-L-4-bromophenylalanine-OH were purchased from Synthetech (Albany, OR). APAE was synthesised in house as previously reported. ${ }^{5}$

All peptides were assembled semi-automatically by using 9-fluorenylmethoxycarbonyl/tert-butyl (Fmoc/tBu) solid-phase peptide synthesis (SPPS) on an ACTIVO-P14 Peptide Synthesizer (Activotec, Cambridge, UK).

\section{Attachment of Fmoc- $\beta$-alanine-OH to 2-CTC Resin}

2-CTC resin (70 mg, $0.1 \mathrm{mmol}$, loading: $0.89 \mathrm{mmol} / \mathrm{g}$ ) was pre-swollen for $5 \mathrm{~min}$ in $\mathrm{CH}_{2} \mathrm{Cl}_{2}(3 \mathrm{~mL})$, and then a mixture of Fmoc- $\beta$-Ala-OH (62 $\mathrm{mg}, 0.2 \mathrm{mmol})$ and DIPEA ( $87 \mu \mathrm{L}, 0.5 \mathrm{mmol})$ in $\mathrm{CH}_{2} \mathrm{Cl}_{2}(3 \mathrm{~mL})$ was added. The reaction vessel was gently agitated at room temperature for 6 $\mathrm{h}$, the mixture was filtered, and the reaction was repeated with fresh reagents for a further $6 \mathrm{~h}$. After completion of the reaction, the resin bed was filtered, washed with $\mathrm{CH}_{2} \mathrm{Cl}_{2}(3 \times 3 \mathrm{~mL})$, and gently agitated with $\mathrm{CH}_{2} \mathrm{Cl}_{2} / \mathrm{MeOH} /$ DIPEA $(8: 1.5: 0.5 \mathrm{v} / \mathrm{v} / \mathrm{v}, 3 \mathrm{~mL})$ for $2 \times 15 \mathrm{~min}$ at room temperature to cap unreacted resin.

\section{Spectrophotometric Quantitation of Fmoc-ß-Ala-OH Loading on the 2-CTC Resin}

Vacuum-dried resin was weighed in two $10-\mathrm{mm}$ matched silica UV spectrophotometric cuvettes (Starna Scientific, Ilford, UK). 20\% Piperidine/DMF (v/v, $3 \mathrm{~mL}$ ) was dispensed into both cuvettes, briefly agitated with an automatic pipette to achieve a uniform suspension, and then left for $10 \mathrm{~min}$ at room temperature. The reference cuvette, containing only $20 \%$ piperidine/DMF ( $\mathrm{v} / \mathrm{v}$ ), was used to zero the spectrophotometer at the wavelength of $290 \mathrm{~nm}$. The absorbances of the two resin-containing cuvettes were quantified, and the loading of Fmoc$\beta$-Ala-OH was calculated by using Equation 1. 


$$
\text { Loading }=\frac{\text { Absorbance }}{(\text { Resin mass } \times 1.75)}
$$

Equation 1 Estimation of first residue attachment on resin; loading is measured in $\mathrm{mmol} \cdot \mathrm{g}^{-1}$

\section{Removal of the $\mathbf{N}^{\boldsymbol{a}}$-Fmoc Protecting Group}

The peptidyl resin was treated with $20 \%$ piperidine in DMF (v/v, 3 $\mathrm{mL}$ ), after which the reaction mixture was agitated for $5 \mathrm{~min}$ at room temperature and filtered. The reaction was then repeated for a further 10 min with fresh reagents. The resin bed was filtered and washed with $\operatorname{DMF}(3 \mathrm{~mL})$ for $4 \times 1 \mathrm{~min}$.

\section{Fmoc-Aa-OH Coupling}

A mixture of Fmoc-protected amino acid (Fmoc-Aa-OH; $0.5 \mathrm{mmol}$ ), HATU (186 mg, $0.49 \mathrm{mmol}$ ), and DIPEA (172 $\mu \mathrm{L}, 1 \mathrm{mmol})$ in DMF ( 1 $\mathrm{mL}$ ) was added to the peptidyl resin $(0.1 \mathrm{mmol})$. The reaction mixture was agitated at room temperature for $1 \mathrm{~h}$ and filtered. The reaction was then repeated for a further $1 \mathrm{~h}$ with fresh reagents. The resin bed was subsequently filtered and washed with $\operatorname{DMF}(3 \mathrm{~mL})$ for $2 \times 1 \mathrm{~min}$.

\section{Fmoc-(S)-2-aminodecanoic Acid-OH Coupling}

A mixture of Fmoc-(S)-2-aminodecanoic acid-OH (40.9 mg, 0.1 mmol), HATU (34 mg, $0.09 \mathrm{mmol})$, and DIPEA ( $70 \mu \mathrm{L}, 0.4 \mathrm{mmol}$ ) in DMF $(1 \mathrm{~mL})$ was added to the peptidyl resin $(0.1 \mathrm{mmol})$. The reaction mixture was agitated at room temperature for $1 \mathrm{~h}$ and filtered. The reaction was then repeated for a further $1 \mathrm{~h}$ with fresh reagents. The resin bed was subsequently washed with $\operatorname{DMF}(3 \mathrm{~mL})$ for $2 \times 1 \mathrm{~min}$.

\section{Coupling of Fmoc-Aib-OH on $\mathbf{N}$-Terminated Resin-Bound Aib}

A mixture of Fmoc-Aib-OH (163 mg, $0.5 \mathrm{mmol}$ ), COMU (214 mg, 0.5 mmol), Oxyma (71 mg, $0.5 \mathrm{mmol})$, and DIPEA (172 $\mu \mathrm{L}, 1 \mathrm{mmol})$ in DMF $(1 \mathrm{~mL})$ was added to the peptidyl resin $(0.1 \mathrm{mmol})$. The reaction mixture was agitated at room temperature for $2 \mathrm{~h}$ and filtered. The reaction was then repeated for a further $2 \mathrm{~h}$ with fresh reagents. The resin bed was subsequently filtered and washed with DMF $(3 \mathrm{~mL})$ for $2 \times 1 \mathrm{~min}$.

\section{Coupling of Fmoc-Xaa-OH at Position 2}

A mixture of the corresponding Fmoc-Xaa-OH (0.2 mmol), HATU (72 $\mathrm{mg}, 0.19 \mathrm{mmol}$ ), and DIPEA ( $70 \mu \mathrm{L}, 0.4 \mathrm{mmol})$ in DMF ( $1 \mathrm{~mL}$ ) was added to the peptidyl resin $(0.1 \mathrm{mmol})$. The reaction mixture was agitated at room temperature for $1 \mathrm{~h}$ and filtered. The reaction was then repeated for a further $1 \mathrm{~h}$ with fresh reagents. The resin bed was subsequently washed with $\operatorname{DMF}(3 \mathrm{~mL})$ for $2 \times 1 \mathrm{~min}$.

\section{Coupling of N-Terminal Butyric Acid}

A mixture of butyric acid ( $47 \mu \mathrm{L}, 0.5 \mathrm{mmol})$, HATU (186 mg, 0.49 $\mathrm{mmol})$, and DIPEA ( $172 \mu \mathrm{L}, 1 \mathrm{mmol})$ in DMF $(1 \mathrm{~mL})$ was added to the peptidyl resin $(0.1 \mathrm{mmol})$. The reaction mixture was agitated at room temperature for $1 \mathrm{~h}$ and filtered. The reaction was then repeated for a further $1 \mathrm{~h}$ with fresh reagents. The resin bed was subsequently washed with $\mathrm{DMF}(3 \times 3 \mathrm{~mL})$ and $\mathrm{CH}_{2} \mathrm{Cl}_{2}(3 \times 3 \mathrm{~mL})$, then left to dry in vacuo.

\section{HFIP-Mediated Resin Cleavage}

The completed peptide chain was cleaved from the resin by treatment with a cleavage cocktail consisting of $\mathrm{CH}_{2} \mathrm{Cl}_{2} / \mathrm{HFIP}(4: 1 \mathrm{v} / \mathrm{v}, 3 \mathrm{~mL})$ for $30 \mathrm{~min}$ with gentle agitation at room temperature. The mixture was then filtered, and the reaction was repeated for a further $30 \mathrm{~min}$ with fresh reagents. The filtrate was partially concentrated under a gentle stream of $\mathrm{N}_{2}$, reconstituted in $\mathrm{H}_{2} \mathrm{O} / \mathrm{CH}_{3} \mathrm{CN}(1: 1 \mathrm{v} / \mathrm{v}, 10 \mathrm{~mL})$, and then lyophilised.

\section{Late-Stage Solution-Phase Installation of C-Terminal APAE}

The lyophilised peptide $(0.1 \mathrm{mmol})$ was pre-dissolved in DMF, and a mixture of DIC (0.5 mmol), 6-Cl-HOBt $(0.5 \mathrm{mmol})$, APAE·2TFA salt $(0.3$ $\mathrm{mmol}$ ), and DIPEA ( $1 \mathrm{mmol}$ ) was added. The reaction mixture was agitated at room temperature for $12 \mathrm{~h}$, and its completeness was monitored by analytical RP-HPLC and LC-MS prior to purification by semi-preparative RP-HPLC.

\section{RP-HPLC Purification of Culicinin D Analogues}

Purification of the crude peptide was performed on a Thermo Scientific (Waltham, MA) Dionex Ultimate 3000 HPLC instrument equipped with a four-channel ultraviolet (UV) detector at 210, 225, 254 , and $280 \mathrm{~nm}$ by using a semi-preparative C18 column (Waters XTerra MS C18, $10 \times 250 \mathrm{~mm}, 5 \mu \mathrm{m}$; Waters, Milford, MA) at a flow rate of $4 \mathrm{~mL} \cdot \mathrm{min}^{-1}$. Solvent A was $0.1 \%$ TFA in water $(\mathrm{v} / \mathrm{v})$, and solvent $B$ was $0.1 \%$ TFA in acetonitrile $(v / v)$. A suitably adjusted gradient of 5 to $95 \%$ B was used over $90 \mathrm{~min}$. Fractions were collected at 1 -min intervals and analysed by analytical RP-HPLC and LC-MS. Fractions containing compounds with the correct $m / z$ were pooled and lyophilised.

\section{RP-HPLC Analysis of Culicinin D Analogues}

Purity analysis of the title peptides was performed on a Thermo Scientific (Waltham, MA) Dionex Ultimate 3000 HPLC instrument equipped with a four-channel UV detector at 210, 225, 254, and 280 $\mathrm{nm}$ by using an analytical C18 column (Waters XTerra MS C18, $4.6 \times$ $150 \mathrm{~mm}, 5 \mu \mathrm{m}$; Waters, Milford, MA) at a flow rate of $1 \mathrm{~mL} \cdot \mathrm{min}^{-1}$. Solvent $A$ was $0.1 \%$ TFA in water (v/v), and solvent $B$ was $0.1 \%$ TFA in acetonitrile $(\mathrm{v} / \mathrm{v})$. A suitably adjusted gradient of 5 to $95 \%$ B was used over 30 minutes.

\section{LC-MS Analysis of Culicinin D Analogues}

LC-MS spectra were acquired on an Agilent Technologies (Santa Clara, CA) 1260 Infinity liquid chromatograph coupled to an Agilent Technologies 6120 Quadrupole mass spectrometer. An analytical C3 column (Agilent Zorbax 300SB-C3, $3 \times 150$ mm, $3.5 \mu \mathrm{m}$; Agilent Technologies, Santa Clara, CA) was used at a flow rate of $0.3 \mathrm{~mL} \cdot \mathrm{min}^{-1}$. Solvent A was $0.1 \%$ formic acid in water $(\mathrm{v} / \mathrm{v})$, and solvent $\mathrm{B}$ was $0.1 \%$ formic acid in acetonitrile $(\mathrm{v} / \mathrm{v})$. A linear gradient of 5 to $95 \%$ B over 30 minutes was applied.

\section{Cell Lines and Antiproliferative Assays}

Two breast cancer cell lines (MDA-MB-468 and SK-BR-3) were purchased from the American Type Culture Collection (Rockville, MD). Short tandem repeat (STR) phenotyping confirmed the authenticity of both cell lines. Cells were maintained in culture under humidified atmospheric conditions with $5 \% \mathrm{CO}_{2}$ at $37{ }^{\circ} \mathrm{C}$, with $<3$ months cumulative passage from authenticated stocks. MDA-MB-468 and SK-BR-3 cells were grown in Dulbecco's modified Eagle's medium (DMEM) supplemented with $10 \%$ foetal calf serum (FCS). Testing of cell cultures for mycoplasma contamination was carried out by using the PlasmoTest Mycoplasma Detection Kit (InvivoGen, San Diego, CA). The sensitivity of both cell lines to the synthetic culicinin $\mathrm{D}$ analogues was examined under aerobic conditions by means of an $\mathrm{IC}_{50}$ antiproliferative assay. Cells were harvested, counted, and seeded at a density of 2000 cells per well in 96-well Nunc tissue culture plates (Thermo Fisher Scientific, Waltham, MA). Cells were incubated overnight to permit adherence and then exposed to the peptides at threefold serial 
dilution in duplicate for five days. The growth medium was subsequently aspirated and replaced with fresh medium. Cultures were fixed in trichloroacetic acid and then stained with SRB dye. Absorbance was determined at $490 \mathrm{~nm}$. A four-parameter logistic regression was fitted to the absorbance-concentration data, and the $\mathrm{IC}_{50}$ value was calculated by interpolation of the drug concentration that reduced staining to $50 \%$, relative to that of the control well on the same plate. Values are reported as the mean \pm the standard error of mean (SEM) from three independent experiments $(n=3)$.

\section{Conflict of Interest}

The authors declare no conflict of interest.

\section{Funding Information}

This work was supported by the Health Research Council of New Zealand (\#18/219), the Maurice Wilkins Centre for Molecular Biodiscovery, and Uniservices Return on Science.

\section{Acknowledgement}

The authors, in particular J.K.K., would like to acknowledge the support received from members of the Brimble Research Group.

\section{Supporting Information}

Supporting information for this article is available online at https://doi.org/10.1055/s-0040-1706264.

\section{References}

(1) He, H.; Janso, J. E.; Yang, H. Y.; Bernan, V. S.; Lin, S. L.; Yu, K. J. Nat. Prod. 2006, 69, 736 .

(2) Porta, C.; Paglino, C.; Mosca, A. Front. Oncol. 2014, 4, 64.

(3) Hanahan, D.; Weinberg, R. A. Cell 2011, 144, 646.

(4) Zhang, W.; Sun, T.-T.; Li, Y.-X. J. Pept. Sci. 2009, 15, 366.

(5) Hung, K.; Harris, P. W. R.; Brimble, M. A. Org. Lett. 2012, 14, 5784.

(6) Stach, M.; Weidkamp, A. J.; Yang, S.-H.; Hung, K.; Furkert, D. P.; Harris, P. W. R.; Smaill, J. B.; Patterson, A. V.; Brimble, M. A. Eur. J. Org. Chem. 2015, 6341.

(7) Stubbing, L. A.; Kavianinia, I.; Abbattista, M. R.; Harris, P. W. R.; Smaill, J. B.; Patterson, A. V.; Brimble, M. A. Eur. J. Med. Chem. 2019, 177, 235

(8) Kavianinia, I.; Stubbing, L. A.; Abbattista, M. R.; Harris, P. W. R.; Smaill, J. B.; Patterson, A. V.; Brimble, M. A. Bioorg. Med. Chem. Lett. 2020, 30, 127135.

(9) Li, F. F.; Stubbing, L. A.; Kavianinia, I.; Abbattista, M. R.; Harris, P. W. R.; Smaill, J. B.; Patterson, A. V.; Brimble, M. A. Bioorg. Med. Chem. Lett. 2020, 30, 127331.

(10) Kavianinia, I.; Kunalingam, L.; Harris, P. W. R.; Cook, G. M.; Brimble, M. A. Org. Lett. 2016, 18, 3878.

(11) Vichai, V.; Kirtikara, K. Nat. Protoc. 2006, 1, 1112.

(12) Mant, C. T.; Zhou, N. E.; Hodges, R. S. J. Chromatogr. A 1989, 476, 363.

(13) Bartalis, J.; Halaweish, F. T. J. Chromatogr. B 2005, 818, 159.

(14) Bolt, H. L.; Williams, C. E. J.; Brooks, R. V.; Zuckermann, R. N.; Cobb, S. L.; Bromley, E. H. C. Pept. Sci. 2017, 108, e23014.

(15) Chemical Terms (accessed Feb 8, 2021): https://disco.chemaxon.com/calculators/demo/plugins/chemicalterms/

(16) Jiménez, J. C.; López-Macià, A.; Gracia, C.; Varón, S.; Carrascal, M.; Caba, J. M.; Royo, M.; Francesch, A. M.; Cuevas, C.; Giralt, E.; Albericio, F. J. Med. Chem. 2008, 51, 4920. 